\title{
Deep Sea Ostracoda and their Micro-Environmental Characteristics from Upper Abyssal Short Core (2540 Metres Water Depth), Off Visakhapatnam, Bay of Bengal, India
}

\author{
Mohammed Noohu Nazeer \\ Department of Geology, University of Madras, School of Earth and Atmospheric Sciences, Chennai, 600 025, India \\ mohdnoohu[at]gmail.com
}

\begin{abstract}
Deep sea Ostracods and their relationship to the variations in the sedimentological characteristics is the prime focus of the present work. We report two deep sea Ostracod taxa namely Krithesp. and Cytherpteron sp. belonging to suborder Podocopa, order Podocopida, have recovered from the subsurface (core length $33 \mathrm{~cm}$ ) sediments at a water depth of 2540 metres. Throughout the core, fine grained muddy substrate is dominant, which indicates prevalence of low energy condition in the region and the fine sedimentation accounts from the suspended load of shallow region. Along the depth $24-27 \mathrm{~cm}$ in the core, showing an abnormal fluctuation of Organic matter and Calcium carbonate in the region. This, along with the occurrence of broken planktic Foraminifera with well-preserved Benthic foraminifers and Ostracods, lights on to a high turbulence in the surface waters during the period of sediment deposition during the time. Element weight percentage has determined using $\mathrm{EDS}$ for $\mathrm{Mg}, \mathrm{Ca}, \mathrm{Mn}, \mathrm{Fe}, \mathrm{Sr}$ and Ba and the results shows that a different trend in elemental concentration exists between these two species, even though the carapace is calcareous. Ostracod occurrence and distribution denotes that a direct relationship exists between the sediment characteristics, shell chemistry and the water column depth.
\end{abstract}

Keywords: Ostracods, Shell chemistry, Organic Matter, Calcium carbonate, Sand-Silt-Clay

\section{Introduction}

Deep sea Ostracods studies are receiving less attention compared with the other group of microfossils, even though they are capable of deriving valuable datum on paleoclimate, palaeoceanography and paleo salinity. Ostracods are Crustacean microorganisms that have adopted to almost all aquatic and some terrestrial habitats (Smith et al., 2015).This peculiarity of Ostracod species makes them an important proxy over Foraminifera in studying different environments. They do have complex life cycle, adapted to environmental conditions of particular kind needed for them to hatch from eggs, reproduce and grow (Ito and Forester, 2009). Potentially, Ostracod species can yield information on the paleo environment of deep ocean (Anna and Mitchell, 2014). Usually, there is an increase in number of species with increasing salinity (Nishath, 2015 et al.). But salinity alone could never be a factor for Ostracod abundance and diversity. Many previous studies confirmed that sedimentological parameters have a direct influence on the abundance and diversity of species in marine and marginal marine environments.In general, for faunal richness of Ostracods either the sediment should be fine grained or a complex of sand grade with a sorting is needed. Even this could be affected, if the salinity, temperature, oxygen micro variations in sediment grains, water flow etc. changes (Dennis Barker, 1983).The total Ostracoda population is also dependent on the water depth (Baskar et al. 2015). Both water chemistry and sediment chemistry have an influence in the occurrence and distribution of Ostracod shells.

The sampling station (Fig.1) is located at the geographical co-ordinates $17^{0} .05^{\prime} 46^{\prime \prime} \mathrm{N}$ and $83^{\circ} .38^{\prime} 46^{\prime \prime} \mathrm{E}$, from a water depth of 2540 metres. This work is an investigation on the micro environmental behaviours of the area with respect to sediment parameters.

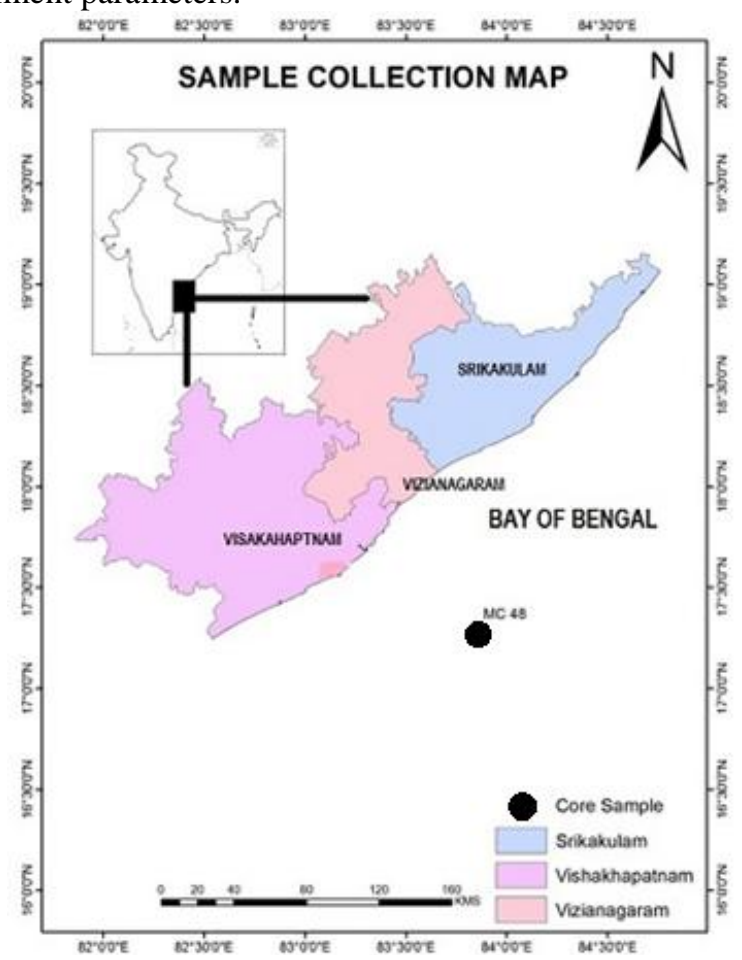

Figure 1: Sample Location map

\section{Materials and Methods}

A short core of length $33 \mathrm{~cm}$, which was collected during the ORV Sagar Kanya cruise SK-308 Leg 1 fieldwork using a multicorer, from Off Visakhapatnam, Bay of Bengal, India, at a water depth of 2540 metres is taken for the present 
study. Eleven samples were obtained after sub-sampling the short core at 3 centimetres interval, which is later subjected tomicropaleontological, sedimentological and shell chemistry analyses.

Proposed classification of Hartmann and Puri (1974) has been followed in the present study for Ostracod identification. Organic matter estimation was done after the titration analysis of Gaudette et al. (1974). Estimation of $\mathrm{CaCO}_{3}$ was carried out, following Loring and Nota (1973). Sand-silt-clay ratios were estimated and calculated using combination of sieving and pipette procedures in accordance with that of Krumbein and Pettijohn (1938).

Ostracods were separated from the sediments, by wet sieving the samples through ASTM 230.An amount of 50gm samples was taken and soaked in distilled water for 24 hours. Soaked samples has been transferred to the 230 ASTM sieve and washed. The samples obtained through the sieve mesh is dried under $50^{\circ} \mathrm{C}$ and the species were handpicked using picking brush. For illustration the SEM photograph of selected hypotypes were taken. EDS is done to determine the general shell chemistry in the Ostracod valves.

\section{Result and Discussion}

\subsection{Ostracod Characteristics}

Two Ostracod species (left under open nomenclature) belonging to 2 genera of suborder Podocopa, Order Podocopida have been identified. Krithe sp. and Cytheropteron sp. are the two forms figured out from the location. Today, Order Podocopida are the widespread and most diverse Ostracods, which could be encountered in all kinds of aquatic environments (Athersuch et al., 1989, Neale, 1988). In numbers, 29 Cytheropteron sp. and 13 Krithe sp. have been recovered from the study location. Distribution of the species is not regular though down core and both the forms reported are morphologically different in all aspects. Krithe sp. is a smooth form with extremely fragile and delicate shell. Cytheropteron sp. however is comparatively harder shell and is well preserved with ornamentations. Secondary pores are well visible in both the species. Morphometrical studies indicates that the average dorso-ventral length of Krithe sp. is $794.41 \mu \mathrm{m}$ and the average anterior- posterior measure is $211.51 \mu \mathrm{m}$ and Cytheropteron sp. is having an average dorso-ventral length of $581.91 \mu \mathrm{m}$ and the average anterior- posterior calculations are $327.42 \mu \mathrm{m}$ to the right of the valve and to left it is tapering to $179.58 \mu \mathrm{m}$ (Fig.2).

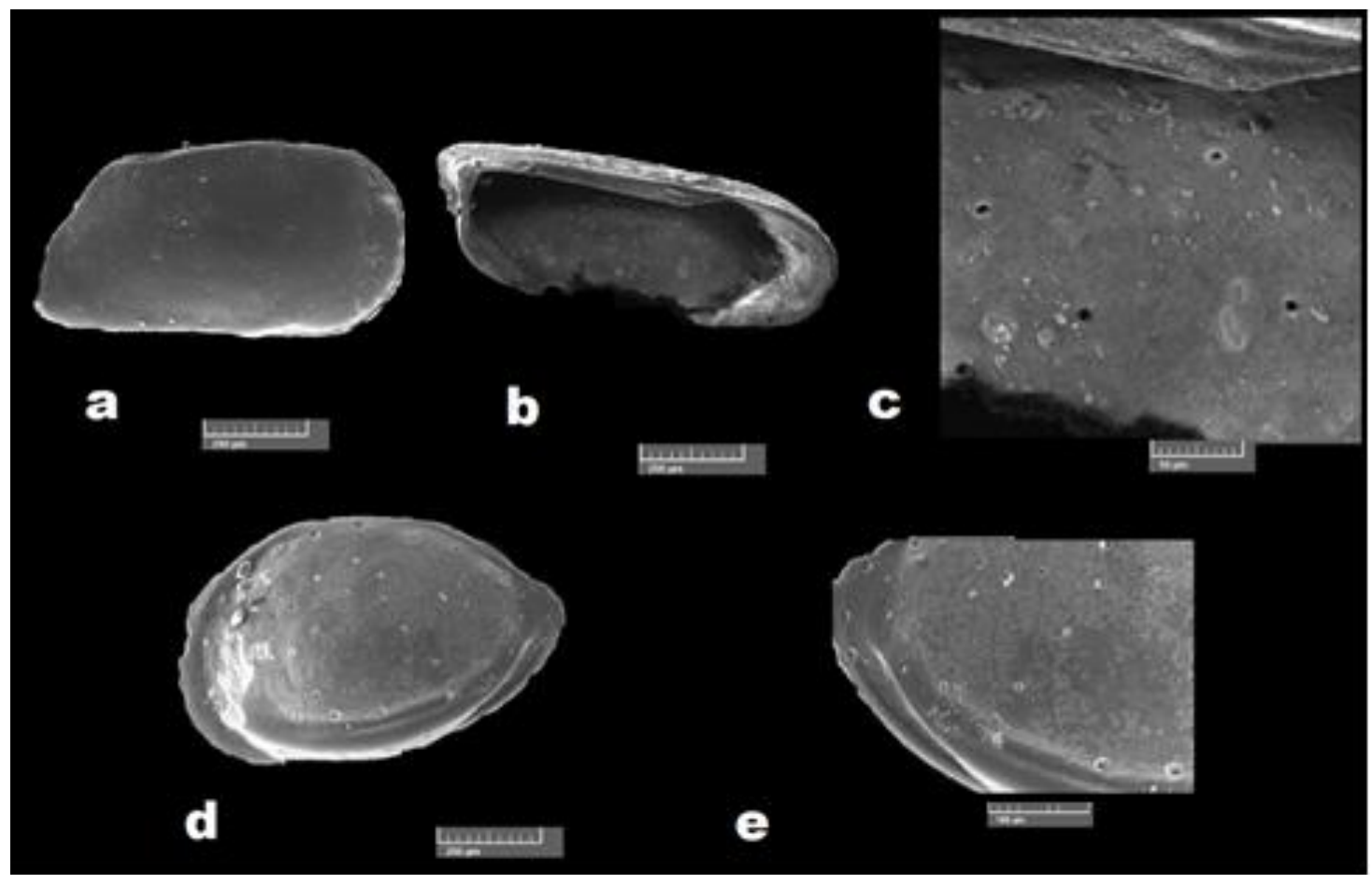

Figure 2: a- Krithe sp R.V External view., b- Krithe sp. R.V Internal view, c- Krithe sp. R.V internal view zoomed, dCytheropteron sp. R.V External view., e- Cytheropteron sp. R.V. External zoomed. (R.V-Right valve)

\subsection{Micro environmental characteristics}

Ostracod abundance and diversity is controlled by many environmental factors such as type of substrate, hydrodynamic conditions, temperature and salinity (Aiello et al. 2006).Species diversity and Ostracod population increases away from the shore with respect to water depth, temperature and salinity (Zhao et al.1985). However, the present study is finding an exact reverse relationship, moving to deep water Ostracod population and diversity is reduced. A check on the sedimentological parameters and shell chemistry throws light into the micro environmental characteristics of the region. $\mathrm{CaCO}_{3}$ studies on the sediments vary from 2.15 to $4.61 \%$, with an average value of $3.72 \%$. Organic matter (OM\%) shows a slight variation, rangingfrom 1.97 to $3.01 \%$, having an average value of $2.45 \%$.

A complete absence of Sand grains has been noted throughout the core, it depicts the lower energy condition of

\section{Volume 10 Issue 1, January 2021}




\section{International Journal of Science and Research (IJSR) \\ ISSN: 2319-7064 \\ SJIF (2019): 7.583}

deposition of the region. The granulometric studies reveals that clay sized particles are dominant than silt particlesin all samples(Table.1). Clay varies from 68.23 to $80.92 \%$ with an average value of $78.74 \%$. Silt percentage ranges between 19.08 to $31.77 \%$.

Table 1: Estimation of Sedimentological Parameters

\begin{tabular}{|c|c|c|c|c|c|}
\hline Sample No & $\mathrm{CaCO}_{3} \%$ & OM\% & Sand \% & Silt \% & Clay \% \\
\hline 1 & 4.13 & 2.21 & 0 & 31.77 & 68.23 \\
\hline 2 & 4.02 & 2.43 & 0 & 23.56 & 76.44 \\
\hline 3 & 3.82 & 2.76 & 0 & 19.08 & 80.92 \\
\hline 4 & 2.95 & 2.31 & 0 & 20.60 & 79.40 \\
\hline 5 & 3.98 & 2.6 & 0 & 19.98 & 80.02 \\
\hline 6 & 3.92 & 3.01 & 0 & 19.17 & 80.83 \\
\hline 7 & 3.90 & 2.88 & 0 & 20.47 & 79.53 \\
\hline 8 & 4.20 & 2.34 & 0 & 19.91 & 80.09 \\
\hline 9 & 2.15 & 1.97 & 0 & 19.8 & 80.20 \\
\hline 10 & 4.61 & 2.12 & 0 & 20.01 & 79.99 \\
\hline 11 & 3.25 & 2.41 & 0 & 19.45 & 80.55 \\
\hline Average & 3.721 & 2.458 & 0 & 21.25 & 78.74 \\
\hline Maximum & 4.61 & 3.01 & 0 & 31.77 & 80.92 \\
\hline Minimum & 2.15 & 1.97 & 0 & 19.08 & 68.23 \\
\hline
\end{tabular}

Clay percentage is comparatively low with respect to other depths in the top core, which implies that the energy condition of the area has been increasing. More silt has been carried from shallower part and deposited in the region and further, a good quantity of clay particles remains in suspension in shallow regions, get transported to deeper part of the ocean.

Organic matter and Calcium carbonate percentage shows a smaller range of fluctuation throughout the core. In sample number 9 both $\mathrm{CaCO}_{3}$ percentage and Organic matter percentage are having least values. The reason may be because of a high surface disturbance and higher surface tubidity, occurred in the surface waters during the sedimentation. Also it could be noted that planktic foraminifera in this particular depth is very less as well as most of them are broken to fragments, with Ostracod Krithe sp. is well preserved, which is a delicate benthic form.

Matrix graphis plotted using past software (Fig.3)to know the relationship between these dimentological parameters. Evident from the plot also the recent times has shown an increase in the energy of deposition in the region. The surface sample is having a higher percentage of silt and comparatively a less percentage of clay devoid of sand.

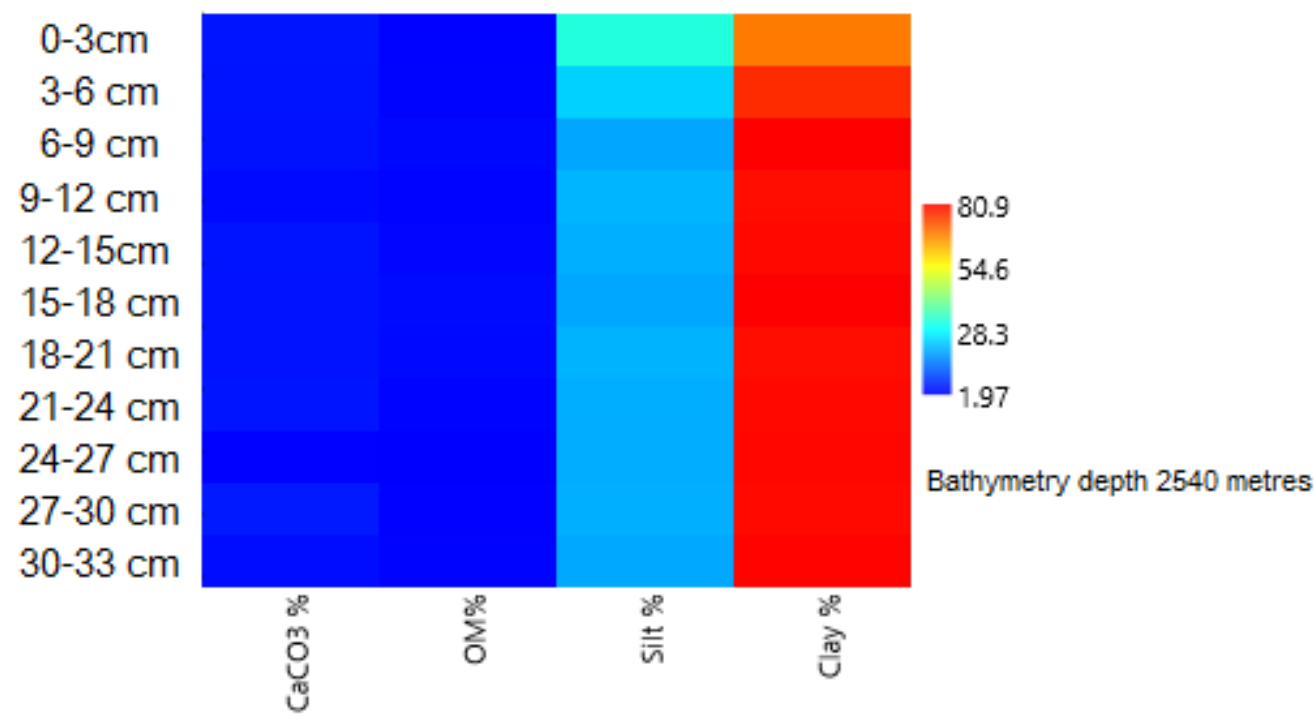

Figure 3: Matrix plot showing $\mathrm{CaCO}_{3} \%, \mathrm{OM} \%$, Silt and Clay percentages

For biological reasons, Ostracods make shells and usually species, follow their own evolutionary physiologic pathways for calcifying their shell (Ito and Forester, 2009). Trace element presence in Ostracoda shells could be related to seasonal environmental changes(Xia et al., 1997a). An illustration in the variation of Elemental percentage in weight percentage has shown in Fig.4. Cytheropteron sp. comparatively have a high percentage of Calcium in their exoskeleton which has resulted in the well preservation of the shell. Krithe sp. is also having Calcium as its dominant composition, but have a huge variation in $\mathrm{Mg}$ with respect to Cytheropteron sp.

Table 2: Elemental weight percentage in Ostracod shell

\begin{tabular}{|c|c|c|c|c|c|c|}
\hline & Magnesium & Calcium & Manganese & Iron & Strontium & Barium \\
\hline Krithe sp. & 7.21 & 91.47 & 0.01 & 0.5 & 0.82 & 0.44 \\
\hline Cytheropteron sp. & 0.6 & 98.03 & 0.5 & 0.5 & 0 & 0.37 \\
\hline
\end{tabular}

\section{*Values in weight percentage (wt\%)}

Calcium is abundant in both the forms, but have a slight difference in its concentration and that difference accounts for Magnesium in Krithe sp. Strontium is absent in
Cytheropteron sp., but a small amount of 0.82 percentage is present in Krithe sp. However, Barium has almost same values in both the species. It is noted that Iron $(\mathrm{Fe})$

\section{Volume 10 Issue 1, January 2021 www.ijsr.net}


imbibition capacity is exactly similar for both the species (Table.2). The difference in the shell composition is the only notable difference, except the morphological variations and believed to be the reason for the occurrence of two different species.

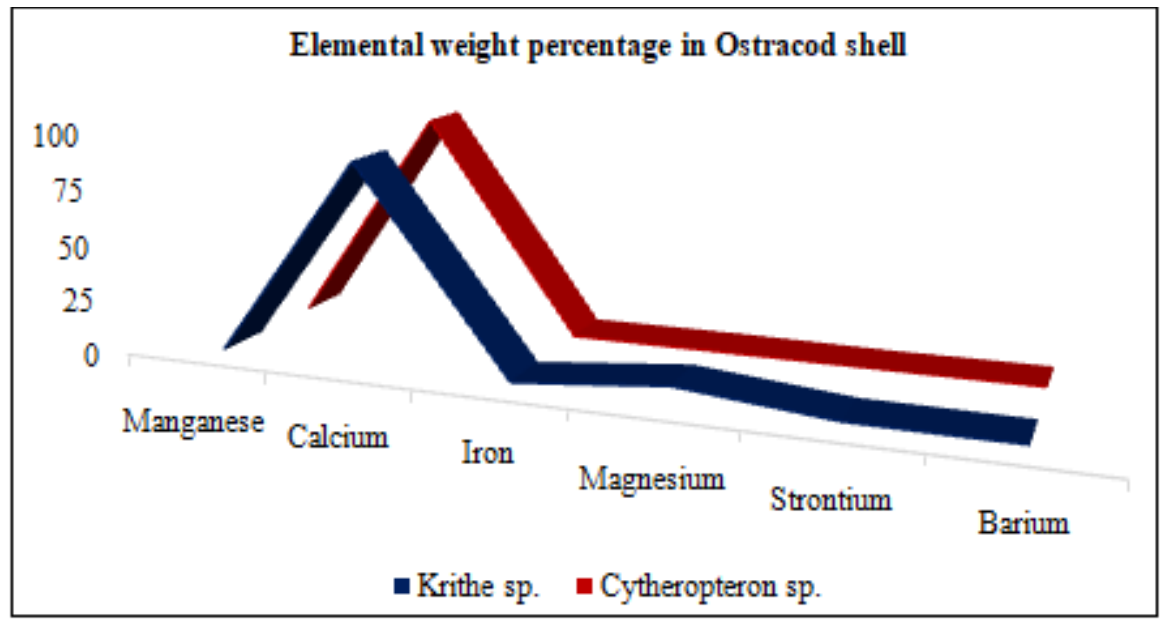

Figure 4: Elemental weight percentage in Ostracod shell

\section{Conclusion}

Entire absence of the Sand grains in the region indicates that a low energy condition, less disturbance in the substrate of the region and the shallow sands are not reaching to this depth. The sand content in fact has been re-deposited to the shallow as well as the coastal zone. The species recovered are typical deep water forms. It is found that shell chemistry has a very important role in the species distribution. No other notable difference in sedimentological parameters has been observed, except for sample number $9(24-27 \mathrm{~cm})$ which could be an impact of a high surface water turbulence and $(0-6 \mathrm{~cm})$ due to an increase in the energy level conditions in the recent geological time. Cytheropteron sp. found from this area are comparatively well preserved and durable, however the form, Krithe sp. recovered are very fragile in nature. This is because of the comparatively higher accumulation percentage of Calcium in the Cytheropteron sp. shell. It is observed that the taxa Krithe sp. and Cytheropteron sp. reported from the study area are near similar to the glacial taxa reported by Anna and Mitchell (2014) from Eastern equatorial pacific. A very low productivity has been observed in this area, expected to be, because of the changes in ocean temperature and increased depth, along with variations in sedimentation.

\section{Acknowledgements}

The financial support extended to the work was funded to Mohammed Noohu Nazeer, by UGC-Maulana Azad National Fellowship, under University Grants Commission is greatly acknowledged. Thanks to Dr. Rajiv Saraswat, Scientist NIO, Goa for the helps and support in various capacities during the field work. Immensely grateful to both the Directors ofSAIF, IIT Madras and NCESS, Thiruvananthapuram, for the permission to utilize SEM and EDS facility. Thanks to Mr. Tharun R, Assistant. Professor, Christ College for the GIS map. Last but not least, thanks to the Head of the Department, University of Madras for the permission to access the departmental facilities.

\section{References}

[1] Athersuch, J., HomeD.J., and WhittakerJ.E., 1989.Marine and brackish water ostracods, Synopses of the British Fauna (New Series), 43, 343pp, 1-7.

[2] Anna Stepanova, Mitchell Lyle, 2014. Deep sea Ostracoda from the eastern equatorial pacific (ODP Site 1238) over the last 460 ka. Marine micropaleontology, 100-117.

[3] Baskar, K., Sridhar, S.G.D., Sivakumar T., Hussain, S.M. and Maniyarasan, S, 2015.TemporalVariation of Physico-chemical Parameters and Ostracoda Population, off Rameswaram, Gulf of Mannar, Southeast Coast of Tamil Nadu, India,Journal Geological Society of India 86, 663-670.

[4] Dennis Barker, 1983. The relationship between Ostracod distribution and sediment grain size,Marine Micropaleontology, 8, 51-63

[5] Emi Ito and Richard M. Forester, 2009.Changes in continental ostracode shell chemistry; uncertainty of cause, Hydrobiologia 620, 1-15

[6] Gaduette, HE., Flight, W. R., Toner, L., and Folger, D. W. 1974. An inexpensive titration method for the determination of organic carbon in recent sediments, Journal of Sedimentary Petrology, 44, 249-253.

[7] Giuseppe Aiello, Diana Barra, Coppa M.G., Valente.A, Zeni.F., 2006. Recent infralittoral Foraminferida and Ostracoda from the Porto Cesareo Lagoon (Ionian Sea Mediterranean) Bolletino della Societa Paleontologica Italiana 45(1),1-14.

[8] Hartmann, G. \& Puri, H.S.,1974. Summary of Neontological and Paleontological Classification of Ostracoda, Mitt. Hamb. Zool. Mus. und Inst., 70, 7-73.

[9] Krumbein, W. C., and Pettijohn, F. J. 1938. Manual of Sedimentary Petrography. Appleton Century Crofts, New York, 549.

[10] Loring, D. H., and Nota, D. J. G. 1973. Morphology and sediments of the Gulf of St. Lawrence, Bulletin of the Fisheries Research Board of Canada, Bull. 182, 147. 
[11] Nishath. M. N., Hussain S.M, and Rajkumar. A., 2015.Distribution of Ostracoda in the sediments of the Northwestern part of the Bay of Bengal, India Implications for Microenvironment. Journal of the Palaeontological Society of India Volume 60(2), 27 33.

[12] Neale, J. W.,1988. Ostracods and palaeosalinity reconstruction, in Ostracoda in the Earth Sciences, edited by P. De Deckker, J.-P. Colin, and J.-P. Peypouquet, Elsevier, Amsterdam 126-155.

[13] Smith, A.J., Horne, D.J., Martens, K., Schön, I., 2015. Class Ostracoda. In: Thorp, J., Rogers, D.C. (Eds.), Ecology and General Biology: Thorp and Covich's Freshwater Invertebrates, Academic Press, 757-780.

[14] Xia, J., Ito, E. and Engstrom, D.R. 1997. Geochemistry of ostracode calcite: Part 1. The experimental determination of oxygen isotope fractionation. Geochemica et Cosmochemica Acta. 61(2): 377-382.

[15] Zhao, Q., Wang, P. and Zhang, Q. 1985. Ostracoda in bottom sediments of the South China Sea, off Guangdong Province, China: their taxonomy and distribution. Marine Micropaleontology of China: 296317.

Volume 10 Issue 1, January 2021 www.ijsr.net 